\title{
EL EMPLAZAMIENTO DE IYI(H)
}

Por

ROBERT POCKLINGTON

Uno de los problemas de la antigua geografía del Reino de Murcia que más ha atraído, y sigue atrayendo, la atención de los historiadores y arabistas es la identificación del topónimo $/ y i(h)$, citado en fuentes árabes como nombre de una de las siete ciudades que se entregaron a los invasores musulmanes en abril de 713 mediante el famoso Pacto de Teodomiro, y mandada destruir en la época de la fundación de Murcia (825).

La abundancia y diversidad de las teorías que se han defendido en torno a la ubicación de esta antigua ciudad, situándola en las más diversas partes de las provincias de Albacete, Alicante o Murcia, encuentra su explicación en tres factores: (a) la general escasez de testimonios documentales, que ha dejado amplios márgenes de libertad a la imaginación de los investigadores, (b) la dificultad de fijar la verdadera pronunciación del topónimo, donde pequeñas variaciones ortográficas entre las formas que figuran en los distintos textos y manuscritos árabes corresponden a importantes diferencias fonéticas, $y$ (c) el haber considerado referentes a un único topónimo datos geográficos que forzosamente aluden a la existencia de tres topónimos diferentes, puesto que no hay manera de que un lugar se encuentre al mismo tiempo: (i) cerca de la Vía Augusta en su tramo Elche-Valencia, (ii) a 30 millas al norte de Cieza en el camino de Toledo a Cartagena, y (iii) en las proximidades del "río de Lorca".

El presente trabajo consta de tres partes: (A) presentación de los textos árabes referentes a $l y i(h)$, único punto de partida válido para cualquier hipótesis seria acerca de su antiguo emplazamiento, (B) crítica de las distintas teorías que se han presentado hasta ahora, y $(C)$ defensa de la hipótesis, ya avanzada por M. Gómez-Moreno, de que lyi(h), se hallaba en Algezares, a unos $4 \mathrm{~km}$. al sur de la ciudad de Murcia. 


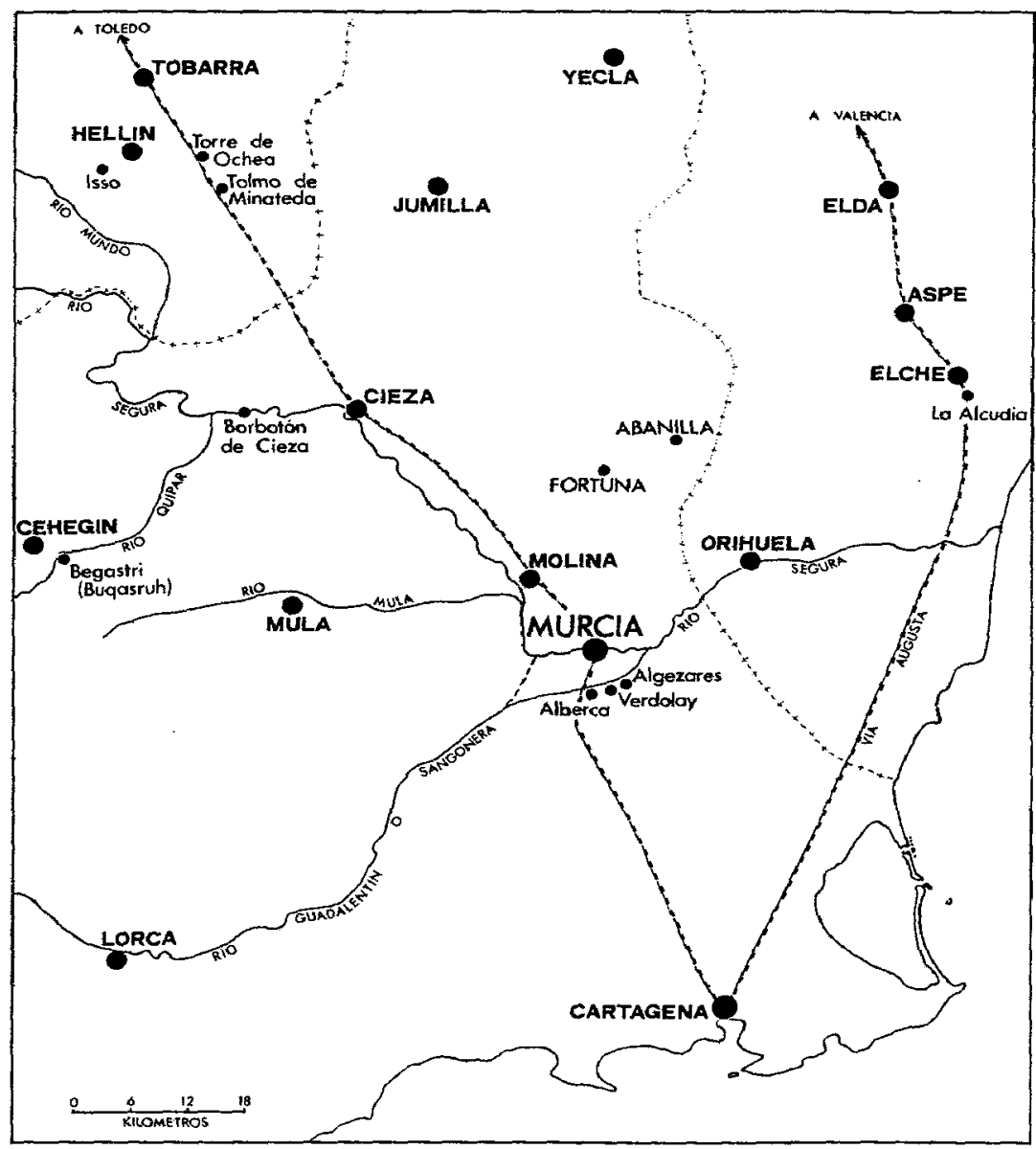

MAPA: UBICACIÓN DE LOS LUGARES CITADOS EN ESTE ESTUDIO. 


\section{FUENTES ÁRABES}

\section{1) El Pacto de Teodomiro}

Se conservan varias versiones, parciales o completas, de este importante documento, en las cuales se encuentra la lista de las siete ciudades acogidas al tratado acordado entre Teodomiro y ${ }^{c} A b d$ al-cAzĩz. Según los autores y manuscritos más fidedignos, una de estas ciudades era $/ y i(h)$ : su nombre aparece en la mayoría de las listas, aunque a menudo bajo una grafía corrupta o incluso casi irreconocible. Las fuentes, por orden de antigüedad, son las siguientes:

Al-`Udrī (m. 1085):

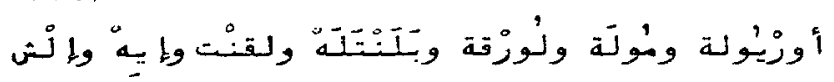

(Awryūla y Mūlá y Lūrqa y Balantala y Laqant e lyih e IIš) (1).

De todas nuestras fuentes para conocer la verdadera pronunciación del topónimo, al-'Ud dri ofrece las mayores garantías de fiabilidad. Además de ser su versión del Pacto la más antigua de todas las que tenemos a nuestra disposición, parece casi seguro que el manuscrito que se conserva es el autógrafo. La vocalización completa de todos los topónimos menos conocidos demuestra que el autor sabía muy bien cómo se pronunciaban. Por este motivo hemos adoptado su transcripción: lyi(h) - con $h$ muda - para representar el topónimo en este estudio.

Ibn al-Jarrāṭ (m. 1185):

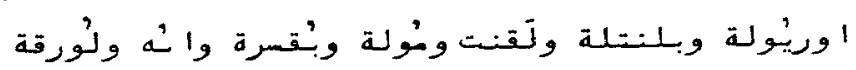

(Awyūla y B.I.nt.la y Laqant y Müla y Buq.sr.h e l.uh y Lūrqa) (2).

Esta lista fue tomada por Ibn al-Jarrăt de una parte, hoy perdida, de la obra genealógica de al-Rušâțī (m. 1147), donde se hallaba transcrito el Pacto entero. Al-Dabbī y al-Garnāți también tomarían sus versiones del Pacto de alRušăți (3). En un reciente trabajo (4), hemos defendido la hipótesis de que al-Rušāți copiaría su versión del Pacto de Teodomiro de un manuscrito original o traslado conservado desde siempre en Murcia. Me comunica E. Molina

(1) AHMAD B. 'UMAR AL-cUDHRT, Fragmentos geográfico-históricos, ed. 'A. al-Ahwānī, Madrid 1965, página 5.

(2) IBN AL-JARRĀT, litișār iqtibās al-anwār, fol. 11-B (edición y traducción en preparación por J. Bosch Vilá y E. Molina Lópezl.

(3) Agradezco mucho al Dr. Emilio Molina su amabilidad en comunicarme todo lo referente a los manuscritos de Ibn al-Jarrât y al-Rušâț, tan importantes para establecer la cadena de transmisión de varias de las versiones conocidas del Pacto de Teodomiro.

(4) A. CARMONA y R. POCKLINGTON, Noticia sobre una nueva versión del Pacto de Teodomiro, (en prensa). 
que en el manuscrito de Ibn al-Jarrāț la grafía del topónimo (yil(h) está emborronada: parece leerse l.uh, donde la segunda letra podría ser cualquiera de $\checkmark, b, t, t, n$, ya que su trazo está desprovisto de puntos diacríticos.

Al-Dabbī (m. h. 1200):

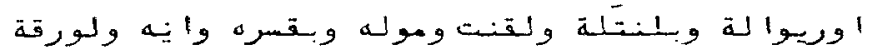

(Awriwāla y B.I.ntala y Laqant y Mūla y B.q.sr.h. e In.h/ly. h y Lürqa) (5).

Como ya se ha dicho, este autor, igual que Ibn al-Jarrāt, tomaría su versión del Pacto de Teodomiro de al-Rušăți, por lo que su transcripción de lyi(h) puede confrontarse con la de Ibn al-Jarrāt con el fin de intentar determinar la forma primitiva que tendría dicho topónimo en el texto de al-Rusāți. La grafía il que ofrece al-Dabbi, evidentemente corrupta puesto que hace que la segunda letra sea a la vez $y$ y $n$, puede tener dos explicaciones: o bien el punto diacrítico que está encima de la y corresponderá a la ọamma (vocal u) de la versión de lbn al-Jarrāt, o bien el copista se equivocó cuando repasaba el renglón, poniendo todos los puntos diacríticos, y creyó que se trataba de la conjunción a i, , (que aparece frecuentemente en el texto del Pacto, siendo precisamente ésta la palabra que sigue al último topónimol; luego, al darse cuenta de su error, añadiría los dos puntos de la $y$, sin llegar a borrar el otro punto equivocado. Cualquiera que sea la verdadera explicación, las formas de Ibn al-Jarrāṭ y al-Dabbī parecen remontar a una transcripción inicial: $l y u(h)$.

\section{Al-Garnāțī (1298-1359):}

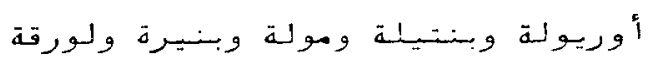

(Awryūla y B.nt.yla y Mūla y B.n.yra y Lūrqa) (6).

La versión del Pacto de Teodomiro que al-Garnāți incluyó en su comentario de la Qașída Maqșüra de Hazīm al-Qarțāyannī fue descubierta recientemente por Alfonso Carmona (7), y también remonta a al-Rušāțī. Desafortunadamente al-Garnāți no supo interpretar todos los nombres de las ciudades, y después de decir que eran siete cita solamente cinco, suprimiendo por completo lyi(h) y Laqant y deformando gravemente las graflas de Balantala y $\mathrm{Bu}$ qasruh.

(5) Kitāb bugyat al-multamis, ms. 1676 de la Bibl. del Escorial, fol. 84v; utilizo la fotografía publicada en: E. MOLINA LÓPEZ y E. PEZZI, Últimas aportaciones al estudio de la Cora de Tudmír (Murcia), Cuadernos de Historia del Islam, n. $7(1975-6)$, frente p. 110

(6) AL-SARĪF AL-GARNĀṬT, Kitāo rafc al-huŷub al-mastūra fĩ mahāsin al-Maqșüra, 1 a ed. imprenta al-Sa¿āda, El Cairo 1925 (1344 h.\}, vol. II, p. 167

(7) Ver: A. CARMONA Y R. POCKLINGTON, op. cit. 
Al-Himyarī (ss. XIV-XV):

De la parte de la obra de este autor referida a la Península Ibérica disponemos de dos ediciones, donde la de E. Lévi-Provençal (1938), preparada a partir de cuatro manuscritos magrebíes, muestra importantes diferencias respecto a la de Ihsān 'Abbās (1980), quien utilizó dos manuscritos orientales. Estas diferencias son de especial relevancia en la lista de las siete ciudades del Pacto de Teodomiro:

Ed. 1938:

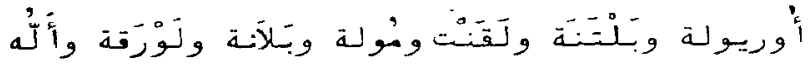

(Üryūla y Baltana y Laqant y Müla y Balāna y Lawraqa y Alluh) (8).

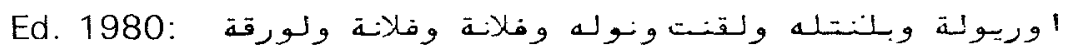

(Awryūla y B.I.nt.la y Laqant y N.w.la y Fulāna y Fulāna y Lūrqa) (9).

La versión del Pacto que recoge al-Himyart es, como ya hemos demostrado en otro estudio (10), la misma que se encuentra en al-Ḍabbī y al-Garnāțī, aunque algo más defectuosa. Al-Himyarī también debió tomarla de al-Rušăți, o de un autor que lo utilizó como fuente. De ello se desprende que, a pesar de las apariencias, los topónimos que figuran en el texto de al-Himyari no son más que deformaciones de los que se hallan en al-Dabbĩ o lbn al-Jarrāṭ.

Los manuscritos orientales de al-Himyarī (ed. 1980), muestran unas formas intermedias entre las de al-Dabbi y las de los manuscritos magrebíes de al-Himyarī (ed. 1938). Este autor no debió entender el quinto y sexto topónimos, Buqasruh e lyih, y escribió en su lugar: Fulāna wa-Fulāna "Fulana y Fulana", tal como se lee en la edición de lhsān "Abbās. Entonces, partiendo de esta base, los manuscritos magrebies primero suprimen una de las Fulāna, entendiendo que se trataba de un error de copia anterior; luego convierten la otra Fulāna en B.lāna, paso fácil en la letra magrebí o andalusí donde el punto diacrítico de la $f$ se coloca debajo, y no encima, de su trazo; finalmente reinventan una séptima ciudad al convertir la conjunción a íque viene después de la lista de ciudades en todas las otras versiones del Pactol en a il, , "y Alluh".

Estos hechos nos obligan a concluir que el topónimo /yi(h) no figura en la versión del Pacto de Teodomiro que se conserva en la obra de al-Himyari. Por otra parte, la lectura Allu(h) queda desautorizada, al menos en esta ocasión, por tratarse, no del topónimo que nos interesa, sino de una deformación de la conjunción wa-annahu.

(8) E. LÉVI-PROVENCAL, La Péninsule Ibérique au Moven-Age d'après le Kitäb ar-Rawd al-Micțār... d'lbn ${ }^{\mathrm{c}} \mathrm{Abd}$ al-Muncim al-HimyarT, Leiden, 1938, texto árabe pp. 62-3, traducción francesa p. 79.

(9) IHSÄN CABBĀS, Al-Rawợ al-Mictār fi jabar al-aqțār, Librairie du Liban/Nasser Foundation for Culture, Beirut 1980, p. 132.

(10) A. CARMONA Y R. POCKLINGTON, op. cit. 
Al-Himyari vuelve a hablar del Pacto de Teodomiro en otra parte de su obra, llegando a describir con algún detalle las circunstancias que rodearon la negociación del mismo. En esta ocasión nombra tres ciudades. Según la edición de 1938 éstas son: أوريولة ولتنت وبكانة

(Ūryũla y Laqant y B.lāna) (11), y según la de 1980 son: وريولة ولتَنس

(Awryūla y Laqant e IIš) (12): en ningún caso se incluye lyith).

\section{Crónica del Moro Rasis (s. XIV):}

La obra de al-Rāzí, gran cronista cordobés del s. X, fue traducida, primero del árabe al portugués (hacia 1300), y luego de este idioma al castellano. Contiene una versión parcial del Pacto de Teodomiro en la que se nombran cinco de las siete ciudades:

«Et Abelaçin... lidió con gente de Origuela, et de Orta, et de Valencia, et de Alicante, et de Denia; et quiso Dios assi que los venció, et dieronse las villas por pleitesía..." (13)

Sólo dos de los cinco nombres se traducen correctamente: Origuela y Alicante. Su "Valencia" corresponderá a Balantala, y "Orta" debe ser Lürqa (14), mientras que "Denia» ha de ser una mala lectura de lyi(h). La grafía a 1, (e lyih) tendria, en la letra andalusí de la época, un gran parecido

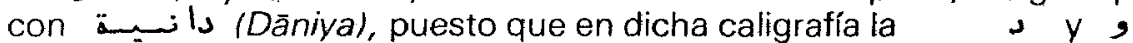
son prácticamente idénticas. Denia era una ciudad muy importante en la época árabe, e indudablemente el traductor árabe la conocería, pareciéndole muy natural que su nombre figurase en el Pacto.

\section{2) La destrucción de (yi(h)}

La presencia del topónimo lyi(h) en la mayoría de las versiones del Pacto de Teodomiro que se conservan, nos permite determinar su pronunciación. que debió ser lyi(h) o lyu(h), pero apenas proporciona ningún indicio en cuanto a su ubicación. Sólo es posible suponer que dicha ciudad se hallaria en la misma zona que las otras, es decir en algún lugar del sureste peninsular.

Las fuentes árabes nos informan que en la época de la fundación de Murcia se mandó destruir $/ y i(h)$, por ser esta ciudad un foco de disturbios, y concretamente el sitio donde se originó la famosa guerra civil entre los mudaríes y

\footnotetext{
(11) Texto árabe, p. 152

(12) Página 462

(13) P. DE GAYANGOS, Memoria sobre la autenticidad de la Crónica denominada del Moro Rasis, en Memorias de la R. Academia de la Historia, t. VIli, Madrid 1852, p. 79.

(14) El traductor, en lugar de a J, entendería a tas posteriores interpretarian el fopónimo Orca como Orta, por infuencia del latín (H)ORTA ahuerta», ya que las letras «t" y "C» eran prácticamente idénticas en la caligrafía de la época, confundiéndosé continuamente en los topónimos.
} 
yemenies. Esta noticia se encuentra en tres autores: al-cUdrī, Ibn 'Idãrî $y$ alHimyari, y nos suministra unas primeras pistas para la localización de (yilh).

\section{Al-CUdrĩ:}

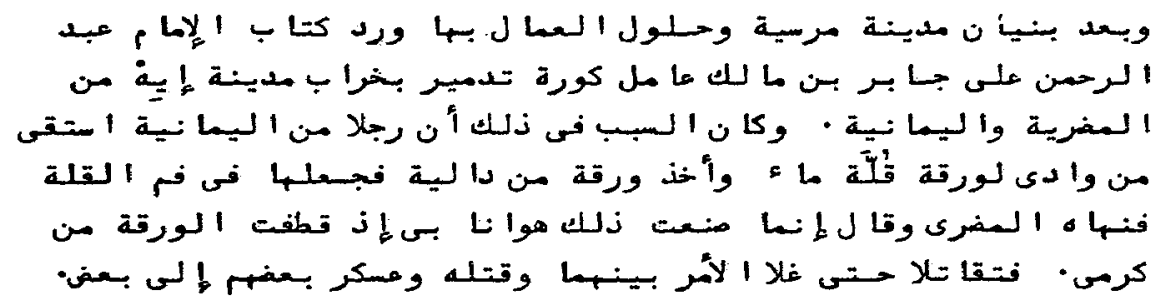

"Y después de la construcción de la ciudad de Murcia, y el establecimiento de los gobernadores en ella, llegó una carta del imām 'Abd al-Raḥmān, dándole órdenes a Y̌ābir b. Mālik, gobernador de la Cora de Tudmìr, que destruyera la ciudad de $/ y i(h)$ de los mudaríes y yemeníes. $Y$ el motivo de eso fue que uno de los yemeníes había llenado un cántaro de agua en el río de Lorca, y cogido una hoja de parra, colocándola en la boca del cántaro. Se lo prohibió el mudari, diciendo: "Tú has hecho eso burlándote de mi, al coger la hoja de mis viñedos". Entonces lucharon hasta que el asunto ya no tuviera remedio, y uno de ellos mató al otro, después de lo cual se generalizó la lucha entre los dos bandos» (15).

Ibn 'Idārī (s. XIII):

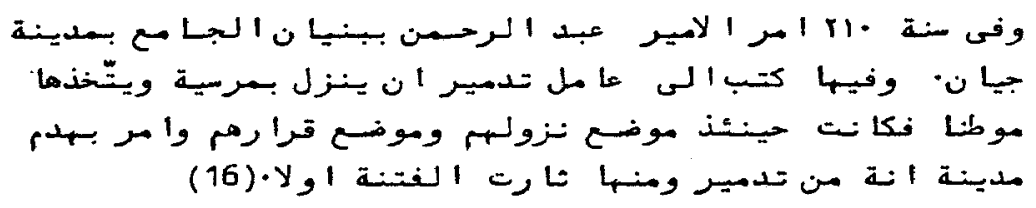

"Y en el año 210 (825-6) el emir 'Abd al-Raḥmān mandó construir la mezquita mayor de Jaén. Y en el mismo año escribió al gobernador de Tudmīr, ordenándole que se trasladara a Murcia y estableciera su residencia allí; y desde aquel momento esta ciudad pasó a ser el lugar de residencia de los gobernadores. Y ordenó la destrucción de la ciudad de Ana de Tudmīr, pues en ella se había originado la guerra civil».

(15) AL-cUDRI, ed. cit., p. 6.

(16) R. DOZY, Histoire de I'Afrique et de l'Espagne, intitulée Al-Bayáno 'I-Mogrib, par Ibn-Adhári (de Marocl. Leiden $1849-51$, t. If, pp. 84-5. 


\section{Al-Himyarĩ:}

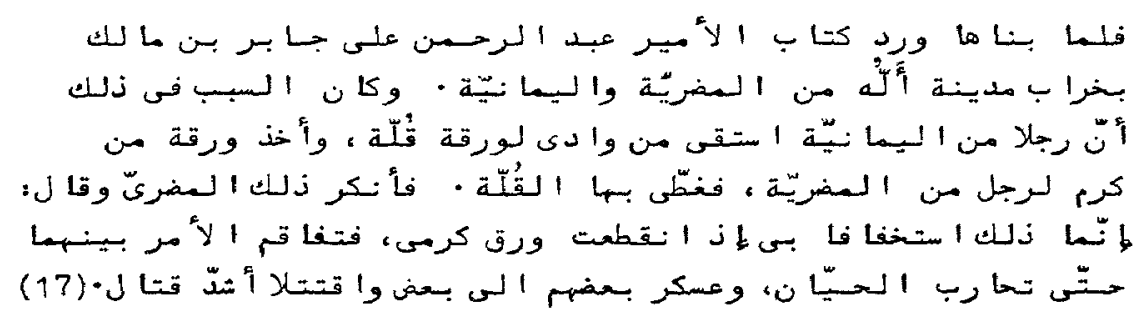

"Y cuando hubo construido la ciudad (de Murcia), le llegó a Ŷābir b. Mālik una carta del emir 'Abd al-Rahmān, ordenándole que destruyera la ciudad de $A / l u(h)$ de los mudaríes y yemenies. Y el motivo de eso fue que uno de los yemenies había llenado un cántaro en el río de Lorca, y cogido una hoja de parra de la viña de uno de los mudaríes, tapando el cántaro con ella. Se opuso el mudarí, diciendo "Tú has hecho (18) eso menospreciándome, al coger (19) la hoja de mis viñedos" . $Y$ el asunto empeoró hasta convertirse en una guerra entre las dos tribus, formándose ejércitos enfrentados los cuales se lanzaron al más violento de los combates".

Los tres textos coinciden en afirmar que se mandó destruir la ciudad de lyi(h) porque fue allí que comenzó la guerra civil entre los yemeníes y mudaríes. Además, especifican que el episodio de la hoja de parra, que originó el conflicto, tuvo lugar junto al río de Lorca. Este último dato es precioso puesto que nos indica que $/ y i(h)$ se hallaba en las proximidades del río de Lorca, es decir el Guadalentín, que desciende desde Lorca, pasando por los términos de Totana, Alhama y Librilla, antes de desembocar en el Segura cerca de Alcantarilla (hoy un cauce artificial lleva su desembocadura hasta un punto más bajol. Este río es el que regaba los legendarios campos de Fundūn (Vega de Lorca) y Sanqunayra (Sangonera), cuya prodigiosa fertilidad alaban de manera insistente las fuentes árabes.

Desde el comienzo de la guerra entre los yemenies y mudaries en el año 207 (822-3), el emir había enviado numerosas expediciones de tropas para imponer el orden, pero cada vez que se marchaban los dos bandos volvían a la lucha. La construcción de la ciudad de Murcia, el traslado de la capitalidad de la Cora de Tudmir a ella, y la destrucción de /yi(h) son tres acontecimientos, íntimamente vinculados en los textos, que han de interpretarse como medidas tomadas por el emir para reestablecer la paz en la cora. (yi(h) era el foco de los problemas, y su devastación en el momento en que se terminó de edificar la ciudad de Murcia implica, con gran probabilidad, el traslado de

(17) Ed. 1938, texto árabe, p. 181.

(18) Falta la palabra en la ed. de 1938; completamos la traducción según el texto de la ed. de 1980 (p. 539 )

(19) La lectura ctas de la ed. de 1980 parece más correcta. 
la población de lyi(h) a Murcia, disposición que permitiría a las dos comunidades en lucha comenzar una nueva vida, lejos de los lugares que recordaban sus antiguas diferencias.

No obstante, este traslado no podía llevar a la población a un punto muy apartado de sus antiguos hogares porque ello implicaría alejarlos de sus tierras, sin las cuales no podían vivir. Iyi(h) debió hallarse, por lo tanto, relativamente cerca de Murcia. Y sus tierras serían, entonces, las del campo de Sangonera, cuya enorme productividad naturalmente favorecería el crecimiento de una ciudad importante, hecho que hasta ahora nadie ha tenido en cuenta Veremos que los demás datos y textos vienen a apoyar estas conclusiones, o al menos no se oponen a ellas.

Por otra parte, en lo que se refiere a la forma del topónimo, cuya importancia quedará patente más abajo, el texto de al-'`Udrī se reafirma en la grafía: ‘ lyi(h), que ya figuraba en su versión del Pacto de Teodomiro. Ibn 'ldărit, según la edición de Dozy, escribe ai ? (Ana/lna/Una/Anna...) No obstante, en unas Correcciones que este autor publicó posteriormente, se incluye la siguiente observación:

"P $P_{i}$, , 1.2. Note de M. Simonet: "Au lieu de 2 ", il faut lire . C'est la ville dont il est question dans le traité entre Abd-al-azíz et Théódemir, 它 du man. de l'Escurial n. ${ }^{\circ} 380$, Jul chez Aboulfeda, Géogr., p. W' , Ello des anciens itinéraires; aujourd'hui c'est un despoblado dans la province de Murcie, district de Montealegre». On pourrait donc lire aussi dans le Bayán». (20)

No apoyaríamos más que en parte la larga serie de identificaciones propuestas por Simonet, aunque tendremos ocasión de hablar de todas ellas en el curso de este trabajo. La última frase de Dozy ha dado a entender (21) que

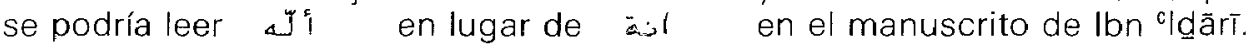
Sin embargo, no es eso lo que quiso decir Dozy: la palabra donc indica que tal lectura se deduciria de las observaciones de Simonet, y no resulta de una revisión del manuscrito. Dozy no rectifica su lectura, sino que dice simplemente que tanto una corrección al como a l serían razonables en vista de las otras formas que toma el topónimo en las distintas fuentes. Si Dozy transcribió inicialmente $\tau_{-1}$, y no se retracta ahora, es porque

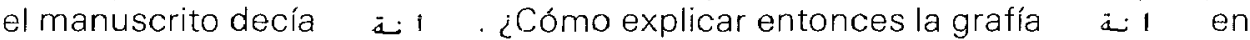
lugar de a l en el manuscrito? Creo que el cambio puede achacare al despiste de un amanuense quien, al repasar este renglón del texto, colocando los puntos diacríticos de las letras, pondría un punto encima del trazo de la $y$, creyendo que debía ser una $n, y$ que se trataba de la frecuente conjunción a 1 ánnahu "que él..." La presencia de $\underset{z}{-}$ en lugar de - no tiene importancia: todas las demás fuentes terminan el topóni-

(20) R. DOZY, Corrections sur les textes du Bayáno 'T-Mogrib d'lbn Adhári lde Maroct..., Leiden, 1883, pp. 40-41.

(21) E. MOLINA LÓPEZ y E. PEZZI, Op. cit., Apéndice lif. 
mo en $\quad-\quad$; se deberá a otra corrupción, probablemente posterior al paso de $\equiv-a \quad$ a Nada se opone, por lo tanto, a que la grafía $a_{-} 1$ remonte a una anterior $\& 1$, es decir lyi(h) olyu(h).

La forma al Allu(h), que figura en ambas ediciones de al-Himyari, es más problemática ya que la uniformidad de la grafía en los distintos manuscritos reduce la posibilidad de que sea una corrupción. No obstante, observamos que, en la parte del texto donde aparece a i la versión de al-Himyari sigue la de al-' ${ }^{\complement} U \underline{d}$ rī al pie de la letra. Entonces, en vista de que el texto de al'cudrī es dos o tres siglos más antiguo, y además muy fidedigno en cuanto a la transcripción y vocalización de los topónimos, forzosamente hemos de otorgar mayor crédito a la forma que recoge al-cudrT, y considerar la de al-Himyarī errónea.

\section{3) Otras referencias a lyi(h)}

\section{Al-Zuhrī (s. XII):}

El siguiente extracto forma parte de una descripción del curso del río Segura. Después de hablar del estrecho de Almadenes (entre Calasparra y Ciezal, el autor dice:

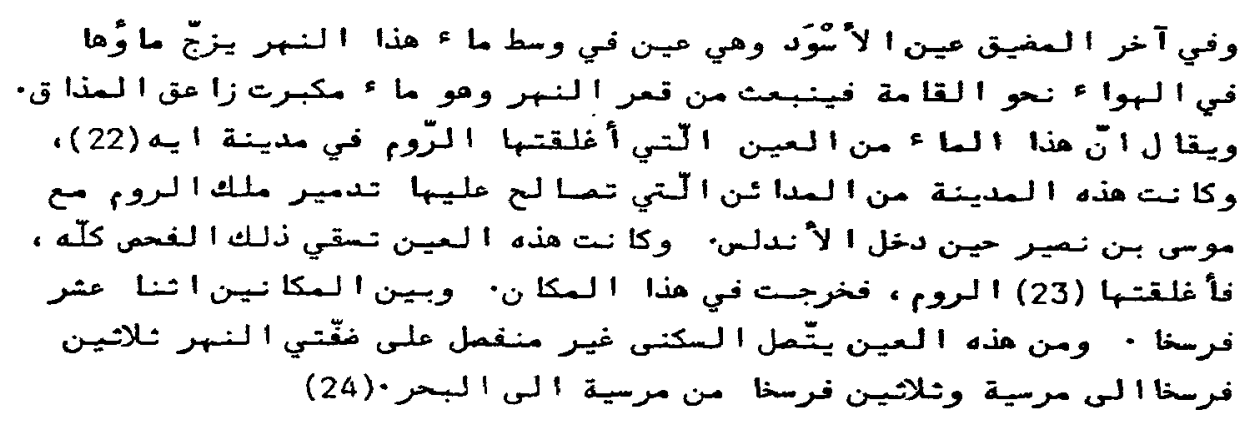

(r) al final del estrecho (de Almadenes) se encuentra la Fuente del Negro. Es una fuente cuyo caudal, en medio del agua del río, salta al aire hasta aproximadamente la altura de un hombre, surgiendo del fondo. Su agua es sulfurosa y de desagradable sabor, y se dice que procede de la fuente que los cristianos cegaron en la ciudad de lyi(h). Ésta fue una de las ciudades sobre las que pactaron Tudmir, el rey de los cristianos, y Mūsà b. Nuṣayr, cuando éste

(22) Var.: أ بـدة

(23) Var.:

(24) M. HADJ-SADOK, Kitāb al-Djacrāfiyya. Mappemonde du calife al-Ma'mūn reproduite par Fazari (II/o/lX" siècles) rééditée et commentée par Zuhrī (V/e/X/le s.l, texte arabe établi avec introduction en français (résumée en arabe) par M. Hadj-Sadok. Bulletin d'Etudes Orientales, tome XXI, 1968, Damasco, p. 207. 
entró en la Península Ibérica. Dicha fuente regaba todo aquel campo, y los cristianos la obstruyeron y salió en este lugar; entre los dos lugares hay una distancia de doce parasangas. Y desde esta fuente los lugares habitados se suceden ininterrumpidamente sobre ambas orillas del río por un espacio de treinta parasangas hasta Murcia, y otras treinta parasangas desde Murcia hasta el marn.

La fuente descrita por al-Zuhrī existe aún; de hecho, hay en el lugar varios manantiales o "borbotones" de características similares, como señala el padre Yelo (25), quien conoce bien el paraje, aunque las aguas ya no saltan al aire como parece que lo hicieran en el tiempo de al-Zuhri. La historia de que la fuente brotó allí cuando los cristianos cegaron otro nacimiento de aguas en $/ y i(h)$, responde sin duda a una leyenda local, concebida para justificar la existencia de tan maravilloso fenómeno; el sabor acre de las aguas se asociaría en sus mentes con el humo, las llamas y las cenizas de la lyi(h) destruida. La distancia indicada, doce parasangas $\{50-60 \mathrm{~km}$.$) , entre la Fuente del \mathrm{Ne}-$

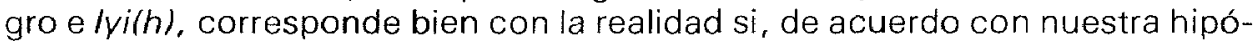
tesis, lyi(h) se encontraba en las cercanías de Murcia.

Se argumentaría, con alguna razón, que las distancias mencionadas en al-Zuhrī son poco dignas de crédito ya que, por ejemplo, dice que había 30 parasangas $(120-150 \mathrm{~km}$ ) entre la fuente y Murcia, y otras tantas entre Murcia y el mar, cuando las distancias reales no llegan a la mitad de eso. Por otra parte, antes de su descripción de la Fuente del Negro, anota que el estrecho de Almadenes tiene una longitud de 4 parasangas $(16-20 \mathrm{~km})$, cuando su verdadera longitud es de $4-8 \mathrm{~km}$. (26). Sin embargo, cuando dice, unos renglones antes, que la confluencia de los ríos Segura y Mundo distaba doce parasangas de Murcia --unos 50-60 km.--, acierta prácticamente porque la distancia real es de $60-65 \mathrm{~km}$.

Estas divergencias se deben, sin duda, a que al-Zuhrī utilizó distintas fuentes, en unas de las cuales las distancias venían expresadas en millas, y en otras se medían en parasangas (leguas). Si, en lugar de contabilizar 30 parasangas entre la fuente y Murcia, y entre Murcia y el mar, entendemos $30 \mathrm{mi}-$ llas $(45-50 \mathrm{~km}$.), llegamos muy cerca de la verdad. Si entendemos que la longitud del estrecho debía de ser 4 millas (unos $6 \mathrm{~km}$.), de nuevo acertamos. Por otro lado. las doce parasangas entre la confluencia Mundo-Segura y la ciudad de Murcia son, efectivamente, parasangas, como ya se ha visto. Así, las doce parasangas entre la fuente e lyi(h) pueden corresponder a unos 18 $\mathrm{km}$. si entendemos "millas", o $50-60 \mathrm{~km}$. si entendemos "parasangas". El segundo valor es el que se ajusta al consenso del resto de ka documentación.

(25) “En la misma salida del desfiladero, curso abajo y en medio del río, brotan unos borbotones de agua, que contrastan con la del río, formando unos espacios oscuros, más perceptibles todavía cuando se enturbia la corriente fluvial... No obstante, en la margen izquierda del río v unos 300 metros más abajo.. brota del lecho fluvial el liamado «Borbotón de Cieza», con las mismas características de los manantiales anteriores, pero con un caudal sumamente importante". A. YELO TEMPLADO, La Ciudad Episcopal de Ello. Anales de la Univ. de Murcia, Fil. y Letras, Vol. XXXVII, n. ${ }^{\circ} 1-2,1978-9$ (ed. 1980), p. 26.

(26) Según la porción que se mide, puesto que el paso se va estrechando progresivamente de oeste a este; los últimos $3 \mathrm{~km}$. son los más estrechos. 


\section{Al-'Ud rī:}

Además de nombrar lyi(h) entre las ciudades acogidas al Pacto de Teodomiro, y de referir las circunstancias de su destrucción, al-c $\cup \underline{d} r i$ también menciona en dos ocasiones un topónimo lyi(h) aún subsistente en su tiempo:

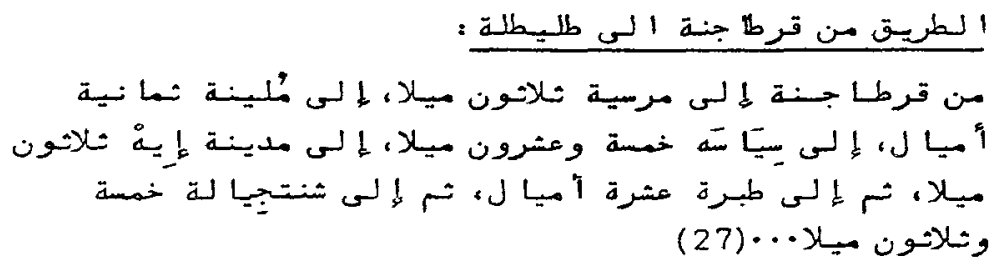

"El camino de Cartagena a Toledo:

De Cartagena a Murcia treinta millas, a Molina ocho millas, a Cieza veinticinco millas, a la ciudad de (yi $(h)$ treinta millas, entonces a Tobarra diez millas, entonces a Chinchilla treinta y cinco millas..."

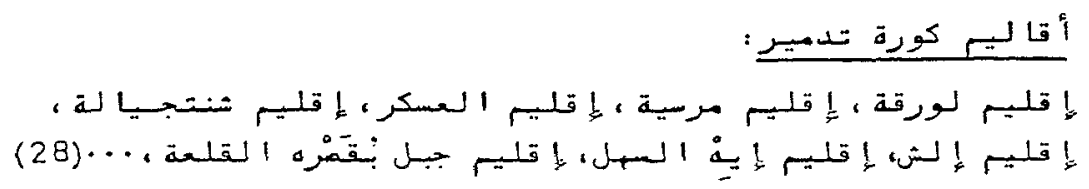

"Los distritos de la Cora de Tudmir:

El distrito de Lorca, el distrito de Murcia, el distrito de al-cAskar, el distrito de Chinchilla, el distrito de Elche, el distrito de lyi(h) del Llano, el distrito de la sierra de Buqașru(h) del Castillo..."

La primera de estas dos citas aporta datos muy precisos que nos obligan, como ya han señalado varios autores, a situar $(y i(h)$ en las proximidades de Hellín. Sin embargo, a tal ubicación se oponen rotundamente las fuentes que informan sobre la destrucción de lyi $(h)$, pues según éstas, dicha ciudad tenía que hallarse relativamente cerca del río de Lorca. Hellín se encuentra a $80 \mathrm{~km}$. al norte de este río, de manera que no existe ninguna posibilidad de reconciliar el conjunto de los testimonios en una sola ubicación.

Se presentan dos salidas: o bien hay que dar por equivocada una de las fuentes, o bien debemos postular la existencia de dos lugares denominados lyi(h). Al-cUdri es un autor muly fiable en las cuestiones toponímicas, y todos los restantes nombres de ciudades y distancias citadas en el itinerario se ajustan a la realidad; no hay ningún motivo por dudar de su testimonio. Por otra parte, la descripción de los acontecimientos que condujeron a la destrucción de lyi(h), y la implicación de que dicha ciudad se hallaba cerca del río de Lor$\mathrm{ca}$, aparecen en varios autores, entre ellos el mismo al-c ${ }^{\circ} \mathrm{d} \mathbf{d} \mathrm{i}$; las distintas

(27) Al-cudrit, ed cit, pp. 3-4

(28) Al-Udrī, ed. cit, o. 10. 
versiones coinciden en favorecer una ubicación próxima a Murcia (el traslado de los habitantes de $/ y i(h)$ desde los alrededores de Hellín hasta Murcia habría sido impracticable ya que, como hemos dicho, hubieran perdido sus tierras, y con ellas su medio de subsistencia; por otra parte, las dos famosas batallas de la guerra civil que estalló entre mudaries y yemeníes en lyilh) tuvieron lugar en Lorca y Murcia, muy lejos de Hellín).

Se impone, por lo tanto, la conclusión de que la ciudad de / yil h), situada entre Cieza y Tobarra, no es la misma que figura en el Pacto de Teodomiro y fue destruida en la época de la fundación de Murcia. Sí puede identificarse, por el contrario, como señala el padre Yelo (29), con el distrito de $/ y i(h)$ del Llano que se cita en el segundo extracto, donde el calificativo "del Llano"se añadiría para distinguirla de la legendaria lyi(h).

El primer intento de determinar la localización exacta de la lyi(h) de Hellín, o "del Llano» se debe a E. Molina López (1971), quien propuso situarla en la falda del cerro del Barrio del Toladillo, próximo a Isso, a 3 ó $4 \mathrm{~km}$. al oeste de la ciudad de Hellín (30). En este paraje se encuentran los restos de un poblado ibero-romano.

Diez años más tarde Pierre Sillières publicó un importante estudio (31), en el cual fija con alguna precisión el recorrido de la vía romana que unía Cartagena con Toledo - el mismo camino que describe al- ${ }^{c} \bigcup \underline{d} \mathbf{r}$. En el tramo que nos interesa, entre Cieza y Tobarra, la vía pasaba por la Venta de la Oliva, el Puerto de la Malamujer, y Cancarix, alcanzando, a continuación, el Tolmo de Minateda. Pero aquí, en lugar de desviarse hacia el oeste para buscar Hellín e Isso, como proponía E. Molina, la vía subía directamente hacia Tobarra, pasando por la Torre de Ochea, siguiendo el "Camino Viejo de Murcia" y la Rambla de Tobarra. Esta trayectoria se confirma a través del estudio de las fotografías aéreas y especialmente gracias al hallazgo de una nueva piedra miliaria junto al dicho camino, cerca de la Torre de Ochea.

Determinado el trazado de la vía, P. Sillières entonces observa que, según las distancias citadas en al-c $\cup \underline{d}$ rī, lyil(h) debía hallarse en las proximidades del tramo de la vía que se extiende entre el Tolmo de Minateda y la Torre de Ochea. Se trata de una zona rica en yacimientos ibéricos, romanos $v$ visigóticos: «... on pourrait aussi bien opter pour le Tolmo, qui fut une importante agglomération ibero-romaine et wisigothique, que pour la Torre de Ochea, cernée de vestiges antiques et médiévaux, ou pour tout autre gisement encore inconnu de la même zonen (32).

\footnotetext{
129) Op. cit., p. 20

(30) E. MOLINA LÓPEZ, lyyu(h): otra ciudad yerma hispanomusulmana, Cuadernos de Historia del Islam, ก. ${ }^{\circ} 3(1971)$, pp. $67-82$

(31) P SIllı̇ERES, Une grande route romaine menant à Carthagène: la Voie Saltigi-Carthago Nova, Madrider Mitteilungen 23 (1982), pp. 247-257

(32) Op. cit., p. 257.
} 
Habiendo llegado a este punto, el estudio de la toponimia viene a resolver definitivamente la cuestión a favor del Tolmo de Minateda, puesto que, como me ha hecho ver el Dr. Alfonso Carmona, el nombre actual de Minateda se deriva precisamente de la denominación Madinat lyi(h) cla ciudad de

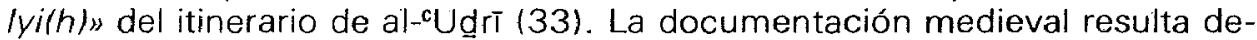
cisiva para clarificar el desarrollo fonético:

«Et a hy otros siete priuilegios del inffante don Alfonso, fijo del rey, que son plomados, et los tres son de otorgamiento de todos los heremaientos (sic) que el rey uos dio, et el quarto es de Felin, et el quinto es de Hyso et de Medina Tea..." (34).

Los tres topónimos citados en esta carta de 1252 son Hellín, Isso y Minateda, todos ubicados muy cerca los unos de los otros en el mapa. La grafía Medina Tea del s. XIII respeta casi a la perfección la forma árabe del nombre, aunque parece indicar que la pronunciación se habia arabizado más entre la época de al-"Udit y la Reconquista, pasando de (yith/ a /lyal, o mejor /Eya/ lla conversión de la última vocal en -a se detecta en numerosos topónimos peninsulares tras su paso por la pronunciación hispano-árabe; cfr. Baza $<B A S$ TI, Elda < ELLO, Cartagena < CARTHAGINE(M), etc.) La transformación de Medina Tea en Minateda ha de ser relativamente reciente, coincidiendo con la debilitación de la - $d$-intervocálica en el castellano popular a partir de los ss. XVII-XVIII. Me comunica Alfonso Carmona que en la actualidad la pronunciación vacila entre Minateda, Minatea y Vinatea.

\section{HISTORIOGRAFÍA RESUMIDA}

\section{Crítica de las diferentes hipótesis que se han defendido en torno a la identificación y ubicación de $|Y|(H)$}

El topónimo se dio a conocer por primera vez en 1770 , cuando $\mathrm{M}$. Casiri publicó el texto del Tratado de Teodomiro incluido en el Kitāb bugyat almultamis de al-Dabbi. Sin embargo, en lugar de lyu(h) leyó "Ota» u "Opta". por lo que Lozano (1794) propuso su identificación con Otoz (Caravaca) (35). Por otra parte, en el mismo año $F$. de Borbón, prefiriendo la lectura "Atsi». tras la agregación de un hipotético nuevo punto diacrítico (es decir Ați según el sistema de transcripción empleada hoy en día), quiso identificar esta ciudad con Guadix, la antigua ACCl (36).

\{33\} La aportación del Dr. Alfonso Carmona me ha sido decisiva para poder aclarar esta cuestión e identificar el topónimo.

(34) J. TORRES FONTES, Colección de documentos para la historia del reino de Murcia, II, Documentos del Siglo XIII. Academia Alfonso X el Sabio, Murcia, 1969, p. 15.

135) M. CASIRI, Bibliotheca Arabico-Hispana Escurialensis, II, Madrid, 1770, pp. 105-6; J. LOZANO, Bastitanía y Contestanía del Reino de Murcia con los vestigios de sus ciudades subterráneas, Murcia, 1794 (Reimpresión: Biblioteca Murciana del Bolsillo, vols, 16-18, Murcia, 1980) vol. 1, Disert. Ift, secc. 15 , pp. 83-93.

(36) Ver: M. GASPAR REMIRO, Historia de Murcia Musulmana, Zaragoza, 1905 (Reimpresión: Bibl. Murc. det Bolsillo, vol. 8, Murcia, 19801, p. 32. 
No sería hasta la segunda mitad del siglo $X \mid X$ que se lograrían los primeros frutos tangibles, gracias a las investigaciones arabísticas de F. Simonet. Al reexaminar el códice de al-Dabbi en el año 1858, se dio cuenta de que la verdadera lectura era "Eio", es decir: $I y u(h), y$, comunicando dicho descubrimiento al académico D. Aureliano Fernández-Guerra, éste cayó inmediatamente en su identificación con la sede episcopal eiotana, mencionada en diversas actas conciliares toledanas del siglo VII (37). Entonces, para completar su hipótesis, Fernández-Guerra profuso una tercera equivalencia, haciendo coincidir la sede eiotana ( de Eion), y la ciudad de Eio del Pacto de Teodomiro, con la mansión Ad-Ello de la Vía Augusta, localizable al norte de Elche. De esta forma situó Eio/lyu( $h$ ) en el Monte Arabí, cerca de Yecla, donde se habían descubierto importantes restos arqueológicos (38).

En la época en que Fernández-Guerra formulaba esta hipótesis (antes de 1875). se conocía ya el texto de Ibn 'Idärī (publ. 1849-51) que habla de la destrucción de $\left(y i(h)\right.$, pero no los de al-Himyart y al- ${ }^{c} U$ dri (publ. 1938 y 1965) que sitúan los acontecimientos junto al río de Lorca. Este nuevo dato hace inaceptable la ubicación de $/ y i(h)$ en las proximidades de Yecla, porque Yecla se encuentra a más de $70 \mathrm{~km}$. del dicho río. Sin embargo, la idea de identificar $/ y i(h)$ con una sede episcopal visigótica, o con una mansión de la Vía Augusta, abre nuevas pespectivas de poder profundizar en el conocimiento de su historia, o determinar con mayor precisión su emplazamiento.

En efecto, obispos que representaban conjuntamente los intereses de las iglesias ilicitana y eiotana/elotana firmaron las actas finales de dos concilios eclesiásticos toledanos celebrados en el S. VII:

"Vinibal Dei miseratione sanctae ecclesiae llicitanae, qui et Elotanae, episcopus haec statuta definiens subscribsi».

Concilio de Toledo VII, año 646 (39).

(Winibal, por la misericordia de Dios obispo de la Santa Iglesia de Elche y de Elo, aprobé y firmé estos cánones).

"Ego Leander ecclesiae [I]licitane, qui et Elotanae, episcopus haec gesta synodica a nobis definita ss.»

Concilio de Toledo XI, año 675 (40).

(Yo, Leandro, obispo de la Iglesia de Elche y de Elo, suscribí estas decisiones sinodales tomadas por nosotrosl.

(37) Así lo cuenta el propio FERNÁNDEZ-GUERRA: Discursos leidos ante la Academia de la Historia en la recepción pública del señor $D$. Juan de Dios de la Rada y Delgado iContestación de A. FERNÁNDEZGUERRA: pp. 111-179), Madrid, 1875, p. 146.

(38) A. FERNANDEZ-GUERRA, Op. cit., pp. 122-159, esp. 123 y 146.

(39) J. VIVES, Concilios Visigóticos e Hispano-Romanos, Barcelona-Madrid, 1963, p. 257

(40) Ibidem, p. 368. 
En otra ocasión un obispo firma en exclusiva representación de la iglesia elotanaleiotana; no obstante, se ha puesto en duda la autenticidad de este documento:

«Sanabilis sanctae ecclesiae Elotanae episcopus ss.»

Concilio de Gundemaro, año 610 (41).

(Sanable, obispo de la Santa Iglesia de Elo, firmé).

La primera cuestión que se ha de plantear con respecto a esta ciudad episcopal es la de la grafía correcta de su nombre. Al preparar su edición de las actas conciliares, J. Vives sólo utilizó, para cada texto, un manuscrito de los muchos que se conservan, y aunque siempre transcribe el gentilicio que nos interesa: "Elotanae", de hecho se detecta una vacilación constante en los diversos manuscritos entre "Elotanae» y «Eiotanae» (42). Esta inconstancia de la grafía se debe a que, en la letra visigótica, la "l» se diferencia de la «i» por "solo un rasguillo inferior... a veces apenas señalado» (43). Esto provoca, como es lógico, numerosos errores de transmisión en nombres y voces que los copistas no conocian, y en tales circunstancias es imposible saber, a través de los manuscritos, si la verdadera pronunciación era Eiotanae o Elotanae. Si deseamos identificar esta ciudad episcopal con la ciudad hispanomusulmana de lyi(h), debemos suponer que la primera de estas grafías es la verdadera: Eiotanae "la de Eio" (44). Volveremos sobre la posibilidad de identificar lyi(h) con Eio más abajo.

Por otra parte, la idea de Fernández-Guerra de equiparar la ciudad de /yi(h) con la mansión Ad-Ello de la Vía Augusta ha de ser rechazada tanto por razones geográficas como filológicas. Esta mansión era una de las que se encontraban en el tramo de la vía entre Valencia y Elche:

$\begin{array}{ll}\text { "Valentia } & \\ \text { Sucronem } & \text { m.p. XX } \\ \text { Ad Statuas } & \text { m.p. XXXII } \\ \text { Ad Turres } & \text { m.p. VIIII } \\ \text { Ad-Ello } & \text { m.p. XXIIII } \\ \text { Aspis } & \text { m.p. XXIIII } \\ \text { Ilici } & \text { m.p. XXIII» (45). }\end{array}$

Ad-Ello ("Junto a Ello") y Aspis, las últimas dos mansiones antes de llici (Elche) se identifican tradicionalmente con Elda y Aspe, y no existen motivos de bulto para rechazar estas ubicaciones. Parece obvio, desde el punto de

\footnotetext{
(41) Ibídem, p. 409

(42) A. FERNANDEZ-GUERRA, Op. cit., p. 146.

(43) Ibidem

(44) La formación de gentilicios con el sufijo -tana era frecuente en aquella época; cfr. Mici - ilicitana, Saetibi - saetibitana, lliberris - liberritana, etc

(45) J. M. ROLDAN HERVÁS, tineraria Hispana, Anejos de Hispania Antiqua, Valladolid, 1975, pp. 51 -2
} 
vista toponímico, que Aspis es Aspe; y el paso fonético del latín Ello al actual nombre de Elda tampoco ofrece dificultades, puesto que la grafía "Ella» que encontramos en diversos textos castellanos del siglo XIII (46) demuestra que el grupo -/d-de Elda procede, por disimilación, de una /./ reduplicada anterior. Se establece, por lo tanto un desarrollo fonético: lat. Ello $>$ ár. ${ }^{*} / l l u(h)>$ ár. tardío ${ }^{*} I I I a(47)>$ cast. s. XIII Ella $>$ Elda.

Las distancias citadas en el itinerario de Antonino parecerían oponerse a estas identificaciones, pues entre la Alcudia de Elche (emplazamiento de la ciudad romana) y Aspe hay unos 13 o $14 \mathrm{~km}$. , y otros tantos entre Aspe y Elda, mientras que el ltinerario indica 24 millas $(=35 \mathrm{~km}$.) en ambos casos; seguramente habría que corregir el texto, y leer um. p. VIlli» en cada ocasión, ya que 9 millas son precisamente $13-14 \mathrm{~km}$.

Establecida la ubicación de la mansión de Ad-Ello en Elda, su identificación con la ciudad de lyi(h) resulta imposible desde la perspectiva geográfica ya que Elda se encuentra a casi $70 \mathrm{~km}$. del río de Lorca, y al mismo tiempo por razones filológicas porque la // reduplicada latina no pudo, de ninguna manera, convertirse en $\mid y /$, ni en el romance primitivo del sur de la Península, ni en el hispano-árabe. Además, la grafía medieval "Ella», al lado de la forma actual Elda, demuestra a las claras que tal cambio fonético no ocurrió, sino que la $/ /$ reduplicada latina perduró en la pronunciación arabizada del topónimo, y en la castellana durante los primeros años tras la Reconquista.

La tesis de Fernández-Guerra de ubicar Eio cerca de Yecla fue aceptada por muchos, en un primer momento, y notablemente por el propio Simonet en su Historia de los Mozárabes de España (48). Pero no por eso dejarían de aparecer nuevas hipótesis. E. Saavedra, en su Estudio sobre la invasión de los Árabes en España (1892), quiso leer, en lugar de lyi(h), "Anaya», cuyo nombre correspondería a la "antigua Thiar del itinerario romano, cerca del convento arruinado de S. Miguel de Salinas, donde subsiste el nombre de la cueva de Anaya, sobre la raya misma de la provincia de Murcia» (49). Sin embargo, las nuevas fuentes árabes se oponen, como hemos visto, tanto a esta lectura del nombre, como a tal ubicación.

M. Gaspar Remiro, en su Historia de Murcia Musulmana (1905), propuso que se leyera Oyyo(h) en lugar de lyu(h), ubicando la ciudad en Ojós (50). El hecho que esta población se encuentra a $18 \mathrm{~km}$. aguas abajo del Borbotón de Cieza se ajustaría bien al dato de al-Zuhrĩ de que $/$ vi(h) distaba doce para-

\footnotetext{
(46) "... el Castiello de Ela" (doc. de 1245), "Ella, con sus entradas e salidas" (doc. de 1253), "Ios lugares de Ella e de Nouella e Elchen (doc. de 1304): J. TORRES FONTES, Op. cit., pp. 6, 15, 161.

(47) Para la conversión de las vocales finales romances en -a, en su paso por el hispano-árabe, compárese el caso de Medina Tea (supra).

(48) F. J. SIMONET, Historia de los Mozárabes de España, 1897-1903. (Reproducción: Ediciones Turner. Madrid 1983, 4 vols.), vol. 1, pp. 55-6.

(49) M. GASPAR REMIRO, Op. cit., p. 32.

(50) M. GASPAR REMIRO, Op. cit., p. 33-5
} 
sangas del dicho manantial: si, en lugar de parasangas, se entiende millas entonces la distancia coincide. Sin embargo, un desarrollo fonético Oyyó(h) = أئís es imposible por numerosos motivos, y la aparición posterior de los textos que sitúan lyilh/ cerca del río de Lorca de nuevo echa abajo la hipótesis, ya que Ojós está a $26 \mathrm{~km}$. de este río.

La teoría de Gaspar Remiro fue la más generalmente aceptada hasta la aparición de la primera edición del texto de al-'Ud dī en 1965. Sin embargo, en $1961 \mathrm{M}$. Gómez-Moreno ya avanzaba una nueva propuesta. Dada la importancia de los yacimientos arqueológicos descubiertos en las vertientes septentrionales de la sierra de la Cresta del Gallo (Algezares-Verdolay-La Albercal, donde se atestigua una importante ocupación humana desde los tiempos argáricos, y en vista de la presencia en Algezares de una basílica de finales del siglo VI que "seguramente fue iglesia adscrita a una sede episcopal", se presenta como muy posible la ubicación de Ello (o sea Elo-Eio-lyj(h)...) en Algezares. La proximidad a la ciudad de Murcia, situada a unos $5 \mathrm{~km}$. al norte, explicaría bien el desarrollo de los acontecimientos históricos relacionados con la destrucción de $/ y i(h)$ en la época de la fundación oficial de Murcia (51). No obstante, esta hipótesis ha recibido, hasta la fecha, pocas adhesiones. Volveremos sobre ella más abajo.

La publicación, en 1965, de los fragmentos del Tarși al-Ajbār de al-cuḍri dio una nueva orientación a las investigaciones, al señalar la presencia de una Madinat lyi(h) "Ciudad de lyi(h)» sobre el camino de Cartagena a Toledo, entre Cieza y Tobarra. Así, en 1969-70, A. Huici Miranda escribiría, refiriéndose a lyi(h): "parece bien claro que no puede aceptarse su localización en Ojós, entre Molina y Cieza, y hay que situarla cerca de Hellín en un despoblado...» (52). Un año más tarde apareció el estudio de E. Molina López que, como ya se ha dicho más arriba, proponía ubicar $/ y i(h)$ en el Barrio del Toladillo, cerca de Isso (Hellín). Y en 1972, J. Vallvé, en su importante estudio sobre la Cora de Tudmir, de nuevo la sitúa en Hellín (53). Ya hemos indicado las razones que nos mueven a identificar esta $(y /(h)$ con el Tolmo de Minateda, distinguiéndola, sin embargo, de la $(y i(h)$ del Pacto de Teodomiro que debía de hallarse junto al rio de Lorca en las proximidades de Murcia.

En el año 1980, el padre A. Yelo Templado presentaba una nueva hipótesis, cuidadosamente documentada y acompañada por un valioso estudio historiográfico (54). En primer lugar, identifica la Madinat (yi(h) del itinerario de al-"Udrĩ con el distrito de "lyi(h) del Llano", admitiendo su ubicación en Hellín, pero negando, como nosotros, su equiparación con la sede eiotana y la ciudad de $l y i(h)$ del Pacto de Teodomiro, destruida un siglo más tarde.

(51) M. GÓMEZ-MORENO, Sugerencias Murcianas, en Homenaje al profesor Cayetano de Mergelina. Murcia, $1961-2$, pp. $441-4$

(52) A. HUICI MIRANDA. Historia musulmana de Valencia y su región, novedades y rectificaciones, 3 tomos, Ayuntamiento de Valencia 1969-70, tomo 1, p. 87.

(53) J. VALLVÉ BERMEJO, La división territorial en la España musulmana (II) La Cora de Tudmĩ (Murcia), Al-Andalus XXXVIl (1972), fase. 1, p. 147.

(54) A. YELO TEMPLADO, Op. cit., pp. 13-44. 
Cuando al-'Udri redactaba su obra, "la venerable Ello no era ya sino un yacimiento arqueológico, mansión yerma e inútil para un itinerarion (p. 20). Para determinar el emplazamiento de esta $l y i(h)$, el padre Yelo utiliza una traducción del texto de al-Zuhri distinta de la nuestra:

"Se dice ciertamente que esta agua de la fuente fue la que canalizaron Ios RUMIES DE LA CIUDAD DE EYO... Esta fuente regaba todo aquel Fahs (vega). La canalizaron los rumies $\vee$ desembocaba por este lugar..." (p. 24).

De esto se desprendería que los cristianos de (yith/ habían construido una acequia desde el Borbotón de Cieza hasta la huerta de su ciudad. Ahora, se continúa utilizando, hoy en día, una acequia que nace del Segura junto a los primeros "borbotones", y riega toda la ribera derecha, desembocando finalmente en el río enfrente de Cieza, junto a las ruinas de la "Villa Vieja" de Cieza. Por este motivo, propone situar Ejo/lyi(h) en la "Villa Vieja» de Cieza.

No obstante, esta hipótesis se apoya exclusivamente en la traducción del verbo il como "canalizar», cuando su verdadero significado es "cerrar, cubrir», hecho confirmado por la variante nuscritos (ver el texto árabe citado más arriba), que igualmente quiere decir "cubrir, llenar, cegar (un pozo)». La idea que expresa al-Zuhrī es, por lo tanto, que el Borbotón brotó en aquel lugar cuando los cristianos cegaron la fuente de lyi(h) (55). Quitado este apoyo la candidatura de Cieza como emplazamiento de lyi(h) se hace insostenible, puesto que: (a) encontrándose a solamente 12 $\mathrm{km}$. de Los Almadenes, resulta difícil reconciliar esta distancia con las doce parasangas del texto, cualquiera que sea nuestra valoración de la uparasanga" (legua o milla); (b) está demasiado lejos del río de Lorca (casi 40 km.); y (c) no se han hallado en la "Villa Vieja" o Cerro del Castillo los restos arqueológicos que correspondieran a una ciudad importante de los siglos VI-IX.

\section{UBICACIÓN DE IYI(H) EN ALGEZARES}

El análisis crítico de la documentación árabe y latina nos ha conducido a desglosar el topónimo que se ha venido llamando Ello en tres diferentes: (1) Ia mansión Ad-Ello de la Vía Augusta, que debe de identificarse con Elda; (2) la ciudad de Madinat lyi(h) o "lyi(h) del Llano», que estaría ubicada en el Tolmo de Minateda; y (3) lyi(h) del Pacto de Teodomro, destruida hacia el año 830, que se encontraría cerca del río de Lorca, y no muy lejos de Murcia. La posible identificación de la sede episcopal eiotana/elotana con uno de estos lugares quedaría por determinar.

(55) Así también traduce J. VALLVÉ BERMEJO (El reino de Murcia en la época musulmana, Rev. de Inst. Egip. de Est. IsI. en Madrid, XX 1979-80, p. 49). La interpretación "canalizar, conducir" se encuentra en otros autores como F. FERNÁNDEZ GONZALEZ (Monumentos de la Cartaginense..., Rev. de Arqueología Española, l(fasc. 2), feb. mar. 1880, pp. 155-6), M. GASPAR REMIRO (Op. cit., p. 34) y E. MOLINA LOPEZ (lyyu(h).., p. 70), quienes parecen haber utilizado el ms. 4999 de la B. N. de Madrid, donde. en lugar de ecolgar". Se trata, sin embargo, de una capia moderna, menos fiable que los manuscritos sobre los que se basó M. Hadj-Sadok para establecer su edición de al-Zuhri 


\section{El topónimo Ayelo}

Los importantes yacimientos arqueológicos que jalonan las faldas septentrionales de la sierra de la Cresta del Gallo, entre los cuales debemos destacar el martyrium paleocristiano de La Alberca, y la basilica de Algezares, demuestran que en estos lugares se hallaba el principal centro de civilización de las proximidades de Murcia en la época antigua y primeros siglos del cristianismo. Si la legendaria (yi(h) se encontraba cerca de Murcia, tenía que hallarse, sin duda alguna, alli, al pie de la sierra.

La existencia, en el siglo XIII, de un topónimo Ayelo, probable diminutivo mozárabe de Eio, precisamente en el corazón de la dicha zona, apoya toponímicamente nuestra hipótesis.

El nombre de Ayelo se cita en una carta de 1266, en la cual el rey don Alfonso X el Sabio ordena que se parta la Huerta por la mitad, quedando el sector occidental en manos de los musulmanes, y el sector oriental en posesión de los cristianos. El camino de Ayelo se dirigía desde el Barrio del Carmen de (Murcia) hasta la sierra meridional, cerca de la frontera entre las dos partes:

«Et la particion de los heredamientos entre los christianos et los moros, tengo por bien et mando que sea fecha en esta guisa: de la puente de Alhariella et desde la mezquita del Alhariella, ally do comiença la carrera del Algebeca et la carrera de Ayelo, que finque la carrera de Ayelo pora los moros et la del Algebeça pora los christianos, et que partan todo el heredamiento que yace entre amas, desde la mezquita sobredicha fasta la sierra a linea derecha por medio. Et lo que cayere contra la carrera del Algebeça que sea de los christianos, et lo que cayere contra la carrera de Ayello que sea de los moros" $\{56\}$.

A/hariella era el nombre del barrio de la ciudad situado en la orilla derecha del río, donde actualmente se encuentra el Barrio del Carmen - la Acequia de Alharilla aún nace allí-, y Algebeça («el Aljezar») es hoy Algezares. Así, la "carrera" o camino de Ayelo debió ser el primero que se dirigía hacia la sierra, al oeste del camino de Algezares. De esto se desprende que Ayelo se hallaba al pie de la sierra, ligeramente al oeste de Algezares: bajo el Santuario de la Fuensanta, Patrona de Murcia, o en Verdolay, bajo el Castillo de la Luz, de construcción árabe. El topónimo vuelve a citarse, y por última vez, en el Libro de la Caza de D. Juan Manuel (1282-1348), donde consta que el nombre de Ayelo también se aplicaba a la sierra en cuyas faldas se hallaba:

«En Murçia ay muchas garças en el río de Segura... Et avn allende del río, por essas açequias que son entre la villa e la Xierra de Yelo». (57)

\footnotetext{
(56) J. TORRES FONTES, Colección de documentos para la historia del Reino de Murcia, l, Documentos de Alfonso $X$ el Sabio. Academia Alfonso $X$ el Sabio, Murcia 1963, pp. 30-31.

(57) D. JUAN MANUEL, El Libro de la Caza, ed. G. Baist, Halle, 1880, p. 71.
} 
No cabe ninguna duda de que el topónimo procede de antes de la Reconquista, puesto que lo citan varios autores árabes. El siguiente verso es de Hāzim al-Qarțāyannī (s. XIII):

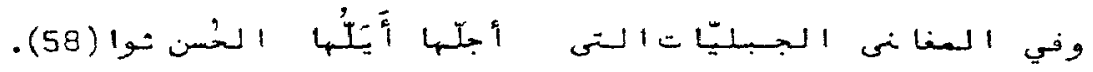

("Y la Belleza hizo un alto en las residencias de la sierra, la más excelsa de las cuales es Ayallu»l.

En su comentario del poema de al-Qarțāŷannī, dice al-Garnāți: "Ayallu es un lugar de Murcia, y nos ha informado un compañero nuestro que lo llamaban Fadlakat al-Uns "la Totalidad de las Alegrias" por hallarse reunida en ese sitio todas las clases de diversiones" (59). Al-Garnāți también transcribe el topónimo: Ayala (60), en lo que coincide con Al-Dabbĩ quien, en su biografía n. ${ }^{\circ} 538$, dice: "Me contó un compañero de mi padre que habia leído en su tumba, en Ayāla - lugar situado al sur de Murcia-, que...» (61). Por otra parte, escribe Aboulfeda (1289-1331), autor del Taqwīm al-Buldān: "Murcia es una de las capitales de Sarq al-Andalus (el Levante Peninsular). Tiene diversos paseos y lugares de esparcimiento, entre ellos al-Rašăqa (el Barrio de la Arrixaca), al-Zanaqāt (62), y Ŷabal l.y.l. (el Monte de lyallu); al pie de este monte se extienden los huertos, y una ¿llanura? sobre la cual se derrama el agua de las fuentes» (63).

Se desprende de estas referencias que Ayallu era uno de los lugares de diversión y esparcimiento preferidos de los musulmanes murcianos. La Reconquista produjo su abandono total ante la necesidad de vivir dentro de las murallas de la ciudad, debido al constante peligro de incursiones hostiles procedentes de los reinos vecinos de Granada y Aragón. No obstante, en tiempos modernos el paisaje de La Alberca-Verdolay ha vuelto a cobrar su antigua importancia como emplazamiento preferido de las residencias de veraneo, testimonio claro de sus ideales condiciones de vida.

La identificación de Ayallu con lyi(h) ya fue planteada por F. Simonet en la nota publicada por Dozy en sus Corrections (vide supra), pero parece que su sugerencia fue olvidada por todos. Recientemente F. García Albaladejo, en un artículo aparecido en 1980 (64), volvió a proponer la misma identificación.

\footnotetext{
(58) Qașida Maqụūra, verso 276: Al-Šarif al-Garnāți. Op. cit., vol. I. p. 125

(59) Ibidem.

(60) Al-Sarīf al-Garnāți, Op. cit, , vol. 1, p. 126

(61) Cita recogida por E. GARCÍA GÓMEZ en sus Observaciones sobre la "Qașída Maqșüra" de Abü-l-tasan Hāzim al-Oarțâyanni, Al-Andalus I (1933), (fasc. 1), p. 99

(62) En la edición se lee: al-Zataqāt, pero corregimos la lectura según al-Qarțâyannī (Oașída Maqșura, v. 3011. El topónimo también figura en un documento castellano de 1277, bajo la forma Asanacat, lo que confirma nuestra interpretación: J. TORRES FONTES, CODOM / (Op. cit., en nuestra nota 56), p. 97

163) Geographie d'Aboulféda, texto árabe publicado por M. Reinaud y el Barón Mac Guckin de Slane. París 1840, p. 179.

(64) F. GARCiA AlBALAdEJo, Hazim "El de Cartagena", poeta del Islam. Rev. Azahara, 9 loct. 1980), Murcia, p. 63
} 
La transcripción del topónimo muestra algunas variaciones en las distintas fuentes árabes, pero las formas romances Ayelo, Ayello y Yelo demues tran que la lectura correcta es Ayállu o Ayālu. El origen pre-árabe del nombre es obvio, presentándose dos etimologías igualmente verosímiles. Por una parte cabe relacionarlo con los tres Aielo o Aiello valencianos (65), y otro Ayelo sevillano (66), los cuales bien pueden derivarse, como propuso M. Sanchís Guarner, del latín AGELLUM "el Campillo", que asimismo originaría los topónimos italianos Ayellu, Ayelli (67). O, por otro lado, puede ser un diminutivo romance en -ello de Eio: *Eiéllo "el Pequeño Eio», cuya forma pasaría al árabe como Ayállu, precisamente la grafía que se documenta con mayor seguridad.

Viene a apoyar la segunda hipótesis, que saca Ayelo de Eio/lyi(h), la existencia, en los alrededores, de otro topónimo quizás también derivado de Eio/ Iyi(h); me refiero al propio Verdolay. De este nombre no he logrado reunir ninguna documentación antigua, lo que es extraño porque tiene aspecto de ser un topónimo antiguo. Aquellos parajes se denominaban, en la Baja Edad Media, las Cañadas de los Valles (68), por lo que no es improbable que se trate de un nombre compuesto del tipo $V a l d e l .$. cuyo último elemento sería un derivado de Eio, con la habitual pérdida de la -o final en el mozárabe murciano. Sin embargo, sólo la aparición de nueva documentación podrá confirmar o negar esta posibilidad.

Pero volviendo a la forma *Eiello "el Pequeño Eio», que hemos postulado como probable etimología de Ayelo, no creo que sería cuestión de identificar este topónimo con Eio/lyi(h), sino tan sólo de situarlo cerca de esta antigua ciudad. Muchas ciudades de la antigüedad tardia desarrollaron satélites que, en algunos casos, con el transcurso del tiempo, pasaron a ser más importantes que ellas mismas, despoblándose la ciudad romana en época árabe; esto ocurrió por ejemplo, en Alicante, Elche y Granada. Ahora, durante el período en el que aún existían ambas poblaciones, el satélite debía de tener un nombre distinto, siendo éste, en ciertas ocasiones, simplemente el diminutio del nombre de la ciudad madre. Tal fue el caso, por ejemplo, de Chinchilla, cuyo nombre moderno se deriva del diminutivo del nombre de la ciudad romana de SALTICI, situada en sus alrededores, hecho que no se ha señalado hasta ahora (69). La forma diminutiva que encontramos en el nombre de otras ciudades también podría deberse a la misma causa: Orihuela, derivado de AURĀRIOLA diminutivo de AURARIA, o el nombre árabe de Toledo: Tulayțula, que

(65) C. BARCELÓ TORRES, Toponimia arábica del País Valencià. Alqueries i casiells, Valencia 1983, p. 70.

(66) Citado a menudo en el Repartimiento de Sevilla. Ver. J. TORRES FONTES, Repartimiento de la Huerta Y Campo de Murcia en el siglo XIII. Murcia 1971, pp. 105-6, nota 56.

(67) W. MEYER-LÜBKE, Romanisches Eymologisches Wörterbuch, 5. ${ }^{a}$ ed. , Heidelberg, 1972, p. 21, número 275b.

(68) Actas capitulares del Concejo de Murcia, 23-X-1379.

(69) De SALTICELLA se sacaría un romance primitivo/mozárabe "Saltechélla que pasaría al árabe local como * Saltachalla: la forma Santayyala que figura en al-UudrT (s. XI) ya tiene la primera sílaba convertida en San-por influencia de los muchos topónimos peninsulares que comienzan Santo- o Santa; la grafía $\hat{y}$ representa el sonido $\mathrm{ch}$; en otros autores árabes encontramos Santaýala, $\hat{Y} i n \hat{y} a l l a$, formas intermedias que clarifican el desarrollo fonético hasta el castellano medieval Chinchiella, y moderno Chinchilla. 
representa un diminutivo romance * Tolétula sacado del latín TOLÉTUM. En la toponimia moderna también hallamos casos paralelos. Por ejemplo, a $7 \mathrm{~km}$. al sur del pueblo de Corvera (Murcia) se encuentra el caserío de La Corverica, y a $5 \mathrm{~km}$. al NO del paraje almeriense de Gafares (Carboneras) está Gafarillos. Entonces, si Ayelo procede, como creemos, de ${ }^{*}$ Eiello, diminutivo de Eio, es más probable que la propia ciudad de Eio/lyi(h) se encontraba en un lugar cercano de la misma ladera de la sierra, en La Alberca o Algezares.

En estas circunstancias es natural replantear la posibilidad, apuntada por Gómez-Moreno, de identificar la ciudad de lyi $(h)$ con la sede episcopal de Eio, situando a ambas en Algezares. Suponiendo que la grafía correcta del gentilicio correspondiente a la sede es eiotana "de Eio», y no elotana "de Elo», no existe ninguna dificultad para identificar su nombre con el de la ciudad citada en las fuentes árabes: Iyu(h) o lyi $(h)$, donde la forma lyu(h), pronunciada /Élo/, sería la más antigua, la que figuraba en la versión original del Pacto de Teodomiro (año 713), mientras que /yi(h), pronunciada /Ėi(i)/, sería la forma corriente en la época de al-c Udri (s. XI), tras la pérdida de la -o final en el mozárabe. La basílica de Algezares se encuentra lo suficientemente alejada $(2-3 \mathrm{~km}$.) para que alli se hallase Eio, y en Verdolay su satélite * Eiello.

El profesor A. González Blanco, especialista en la historia de esta época, me ha hecho el reparo de que Algezares está demasiado lejos de Elche para que una iglesia situada alli se hubiera anexionado a la de Elche, y que es más probable que la sede eiotana/elotana estuviera en Elda. En esta línea, E. Llobregat aporta el dato curioso de que en las proximidades de Elda se encuentra un despoblado de época ibérica, romana y visigótica denominado El Monastil (del latín MONASTÉRIUM), lo que de nuevo apoyaría la ubicación de la sede en Elda (70)

Sin embargo, reduce la fuerza probatoria de este testimonio toponímico el hecho, subrayado por María Jesús Rubiera en su libro Villena en las calzadas romana y árabe, de que el topónimo Monastil ua pesar de su apariencia corresponde al término usado por los árabes de Al-Andalus para indicar una fortificación defendida exclusivamente por musulmanes que querían cumplir el precepto de la guerra santa, y no un monasterion (71). Por otra parte, las grafías eiotana o elotana tampoco resultan favorables a la identificación de esta sede con Elda desde el punto de vista fonológico, pues mientras que el nombre de la sede nunca aparece escrito con $-1 /$-reduplicada, Elda siempre la tuvo reduplicada (la diferencia //I/ era significativa en la época, por lo que debía de quedar reflejada en la ortografía) (72). Está claro que hechos como

(70) E. A. LLOBREgAT CONESA, Teodomiro de Oriola, su vida y su obra, publicaciones de la Caja de Ahorros Frovincial, 17. Alicante 1973, o. 49.

(71) Universidad de Alicante/Ayuntamiento de Villena, 1985, p. 42.

(72) En un estudio titulado Sobre la identificación toponímica de "Elota» (Homenaje a Millás Vallicrosa, Barcelona, 1956, vol. II, pp. 31-40). F. MATEU y LLOPIS propuso ubicar en Elda la ceca levantina de ab l "Élota", que acuñó moneda en los años 1011-15 y 1044-45. Esta tesis se apoya exclusivamente en argumentos toponímicos insostenibles. La lectura "Elotan de la grafía árabe a d es 
estos no bastan para refutar de manera definitiva la hipótesis de que la sede episcopal de Eio/Elo estuviera en Elda, pero desde luego reducen sensiblemente la posibilidad de tal identificación.

Por otra parte, tampoco se puede demostrar de modo concluyente que la sede estaba en Algezares, pero allí al menos quedan los restos de una basílica importante, con baptisterio, que «seguramente fue iglesia adscrita a una sede episcopal»; no nos apoyamos tan solamente en un topónimo de dudosa procedencia, como el Monastil de Elda. El desarrollo fonético Eio $>$ Eiéllo $>$ Ayelo no presenta dificultades, mientras que Elo $>$ Elda sí. En cuanto al alejamiento de Elche, si la basílica y comunidad cristiana de los alrededores de Algezares dejaron de ser lo suficientemente importantes para tener obispo propio, la anexión a la diócesis de Elche era más fácil que a la de Bigastro; esta ciudad se encontraba más lejos de Algezares que Elche $(60 \mathrm{~km}$. frente a 50 $\mathrm{km}$.) y pertenecía a otra comarca geográfica.

Acaso se podría objetar a la ubicación de Eio/lyi(h) en Algezares el que no se han hallado en los alrededores de la basílica los restos de una gran ciudad. Sin embargo, aún no se ha excavado más que la basílica. Me comunica el arqueólogo Sebastián Ramallo Asensio, quien ha hecho prospecciones con vistas a futuras excavaciones en la basílica y en su entorno, que hay señales de un extenso caserío alrededor de la misma. Pero si, como parece desprenderse de la documentación árabe, la población se trasladó de (yilh) a Murcia cuando se fundó ésta, es lógico que apenas quedan restos de aquélla, por el siguiente motivo. No había piedra en Murcia; era obligado traerla de las canteras más próximas, las cuales se hallaban precisamente en la sierra detrás de Algezares. Ahora, como es natural, los nuevos habitantes de Murcia, antes de subir a las canteras a extraer piedra, se llevarían primero la de las construcciones y, en su caso, muralla de lyi(h): cada familia debió desmantelar su casa en Eio/lyi(h) y volverla a edificar en Murcia. Quizás tan sólo escaparía a la depradación la basílica, que posiblemente se convirtiera en santuario, visitado en romería cada año, como en la actualidad se visita el cercano santuario de Nuestra Señora de la Fuensanta, Patrona de Murcia. Esta hipótesis podría parecer inventada ad hoc para explicar la escasez de restos de una ciudad en el lugar, pero cuenta con el respaldo de una fuente árabe cuyo texto, citado por Gayangos en el siglo pasado, hoy está perdido: «Según el autor de Audhahu-l-mesálek (folio 151, verso), Murcia fue construida enteramente por los Árabes con los materiales de una ciudad romana de los alrededores" (73).

puramente hipotética, pudiéndose leer gualmente Al-Wața, Ulūtata, llawațta... y aunque aceptáramos la pronunciación «Elota», su identificación con Elda sería sumamente difícil porque en la época árabe Elda debía de ser El.la o El.10, como ya se ha demostrado. La ceca de ab الس debía de hallarse en otra parte.

(73) Mohammedan Dymasties, p. 377, nota 8 (Cito a través de: A. CARMONA GONZÁLEZ, Murcia, LUna fundación árabe? (Historiografla de una polémica), Miscelánea Medieval Murciana, Xl (1984), pp. 9 65: cita p. 25). 